\title{
DE CRIMINALES A CIUDADANOS: la educación penitenciaria mexicana en el siglo XIX ${ }^{1}$
}

\author{
Antonio Padilla Arroyo ${ }^{2}$ \\ Instituto Superior de Ciencias de la Educación del Estado de México
}

\section{Introducción}

El estudio de la institución y la educación penitenciaria ha sido poco atractivo para los historiadores. En su gran mayoría han privilegiado el estudio de las élites, la fortuna y la alta cultura. En una palabra se han acercado preferentemente a la historia de las cumbres. Historiadores y sociólogos han rehuido los temas indignos. Con todo ha ganado terreno en el mundo de los historiadores el estudio de un material "no noble", aquel que tiene por exponentes a los hombres mediocres. Hay un esfuerzo mayor por remover y descubrir lo cotidiano a través de lo que se fuga de los sujetos individuales. Es decir, se trabaja ya no sobre las grandes figuras o los vastos acontecimientos, sino mediante vidas infamantes, la desviación, lo singular y lo atípico, lo cual permite dibujar la complejidad de lo social. Los célebres trabajos de Michel Foucault en torno al nacimiento de la cárcel y, en general, de las instituciones de internamiento permitió atraer la atención de un público especializado, entre quienes se encuentran un número significativo de historiadores tanto europeos como norteamericanos y latinoamericanos. Estos han volteado su mirada hacia otros campos de la investigación histórica, en particular al tema carcelario el cual se ha visto alimentado por nuevas miradas provenientes de la historia de las mentalidades y la historia social. En gran medida, la historia de las cárceles y de la educación peni-

1 Este texto forma parte de una investigación más amplia titulada "La beneficencia en el marco educativo del Estado de México", que se realiza en el Instituto Superior de Ciencias de la Educación del Estado de México. Una primera versión se presentó en la IX Reunión de Historiadores Mexicanos y norteamericanos, celebrada en la ciudad de México los días 27-29 de octubre de 1994.

2 Docente-investigador del Instituto Superior de Ciencias de la Educación del estado de México, ISCEEM, dependiente del Gobierno del Estado de México. 
tenciaria corresponde a esos espacios malditos, sin estatuto científico, con frecuencia silenciados y excluidos y condenados por la alta cultura porque mediante su estudio y disección se ponen al descubierto la verdad que se fabrica en nuestras sociedades. ${ }^{3}$

El estudio y la comprensión de las ideas y los proyectos en torno al control social, de los miedos y temores que se proyectan mediante ellos y los mecanismos institucionales que se instauran para el ejercicio del poder y la dominación, se complementa con el análisis de la composición de los sectores a los cuales se destinan. La historia social ha permitido recuperar "la otra historia”, la de una franja de la población marginalizada y criminalizada. En este marco se ubica el estudio de la educación penitenciaria. El campo de la educación en las cárceles no puede aislarse de una estructura social determinada ni tampoco puede mantenerse independiente de las ideas y las propuestas de control e higiene social que la justifican y la explican. La comprensión de ambos hechos permite arrojar luz sobre el funcionamiento y las características de ese ámbito educativo, de sus fines y sus medios. ${ }^{4}$

El presente texto trata acerca de cómo y por qué la educación penitenciaria fue motivo de interés y preocupación dentro del proceso de reorganización carcelaria que se produjo en nuestro país, del pensamiento y la realidad penitenciaria en el siglo XIX. En este sentido se pretende analizar su significado y su contenido. Aquí se afirma que la educación en las cárceles se percibía como un proceso de moralización que tenía el propósito de generalizar la moral burguesa, de extender sus preceptos morales. Para lograr tal fin se fijaron los pilares de la moralización: el trabajo terapéutico y la educación. La educación penitenciaria fue parte sustancial de la utopía de la élite política, que pretendía llevar a cabo una metamorfosis social completa en las clases sociales bajas, es decir, convertirlas de clases peligrosas y criminales en clases observado- ras de la ley e insertarlas en la sociedad.

Por ello, la educación penitenciaria tuvo un contenido profundamente propedéutico, así como una función de educación social y moral que haría a los individuos aptos para ser buenos ciudadanos. La fascinación por esa metamorfosis exigía el esfuerzo de conocer y reflexionar acerca de las pasiones

3 Foucault, Michel. Microfísica del poder, Madrid, Las Ediciones de la Piqueta, 1992, p. 87; Farge, Arlette. La vida frágil, México, Instituto Mora, 1994, pp. 7-9; Varela, Julio. Espacios de Poder, Madrid, Las ediciones de La Piqueta, 1991, p. 7.

4 Donzelot, Jacques. "Espacio, trabajo y moralización. Génesis y transformaciones paralelas de la prisión y el manicomio" en Espacios de Poder, Madrid, Ediciones Endymión, 1991, p. 27; Schmitt, Jean Claude. "La historia de los marginados" en Diccionario del saber moderno. La nueva historia, Bilboa, España, Ediciones Mensajero, 1988. 
y los móviles humanos de los delincuentes. De ahí que resulte fundamental el estudio de ciertos rasgos constitutivos de la vida social de la institución penitenciaria: el aislamiento del mundo exterior, la promiscuidad de los recluidos, la programación del conjunto de la vida cotidiana y la observación de una reglamentación única y la ruptura entre gobernantes y gobernados.

\section{El pensamiento social y la secularización de la pobreza}

El origen y formación de la cárcel moderna en México se enmarcó dentro de un profundo debate en torno a la pobreza y los pobres, de una redefinición de las tareas tradicionales de la caridad pública y privada, así como en el diseñó y puesta en práctica de una nueva política social dirigida al control, el cuidado y la atención a los pobres.

Los antecedentes de dicho debate y los procesos sociales que lo acompañaron, se ubican a mediados del siglo XVIII, con la ejercitación de una profunda reforma política y administrativa promovida por las autoridades coloniales que se extendió a todos los ámbitos de la vida social. Uno de los rasgos más notables en el pensamiento y la vida social de la época fue la polémica sobre el papel de la limosna, expresión vital de la caridad, y su paulatina sustitución por la filantropía. El tránsito de la limosna, sostén de todo el aparato institucional auspiciado por la Iglesia católica, a la filantropía fue fundamental dentro del proceso de secularización de la pobreza. Aunque con tibieza se buscaron las causas que la originaban. Al mismo tiempo que se produjo la secularización en el ámbito de las ideas, se admitieron realidades que contribuían a explicarla y con ello impulsar dicho proceso: las desigualdades y, por añadidura, los males que asolaban a la sociedad, en especial la vagancia y la mendicidad. Así en los primeros años de vida independiente se aseguraba que los males provocados por la guerra de independencia estaban a la vista: el licenciamiento de las fuerzas insurgentes y las tropas realistas habían originado un clima de inestabilidad económica, social y política que se reflejaba en una multitud de hombres que tenían como única forma de vida el pillaje y la inmoralidad, "sin otra preocupación que la que proporcionaba la ejercitación de sus vicios". Tal estado social era sufrido por los "pueblos aterrorizados" en medio de su impotencia para detener las fechorías y crímenes que cometían a plena luz del día. Frente a este panorama desolador, Muzquiz aclaraba que había dispuesto algunas medidas para cortar esos males tales como la identificación) persecución de los vagos y los malentretenidos, así como enviarlos a las cárceles. Años más tarde, el sucesor de Muzquiz en el gobierno estatal, 
Lorenzo de Zavala, asimismo destacaba que la miseria en que vivía gran parte de la población se debía a la enorme desigualdad de fortunas y a los hábitos de muchos años de "andar errantes y armados", lo cual creaba un clima propicio para fomentar las revoluciones. ${ }^{5}$

La pobreza y los pobres estarían sometidos a una mirada que forjó diversas imágenes de repulsión y rechazo social, pero también de temor y preocupación. A finales del siglo XIX el estudio sobre las causas de la pobreza y los tipos de pobres guardaba gran similitud con las ideas de principios de siglo acerca de las condiciones que la originaban, aunque habían cambia- do las circunstancias en las cuales se forjaban esas explicaciones. Una de las coincidencias más sobresalientes entre la mayoría de los autores fue que la pobreza tenía entre sus principales causas la devastación que había padecido el país con la guerra civil y la invasión extranjera. Sus secuelas se manifestaban en la ausencia de inversión y la desorganización de la industria, el comercio y la agricultura con la consecuente expulsión de la mano de obra que buscaba donde ocuparse y, ante la imposibilidad de encontrar empleo, recurriera a actividades que revelaban la gravedad de la crisis social que enfrentaba la nación: la mendicidad generalizada, la vagancia, la prostitución, los juegos de azar y, en el último escalón de las conductas antisociales, la delincuencia en todas sus manifestaciones. El periódico La Libertad hizo notar que el problema fundamental del país era la inseguridad pública porque había impedido atraer la inversión de los ricos y éstos preferían emigrar a otros países. El temor a ser asaltados y robados explicaba su indiferencia y apatía para promover el progreso del país y, demostraba, a su vez, el grado de desorganización del y la falta de patriotismo de los ricos.

Por su parte, el periódico La Ilustración Católica justificaba tal actitud y explicó que, en todo caso, la anarquía que padecía el país se debía a las doctrinas liberales y al desquiciamiento que provocaron en el país. ${ }^{6}$

5 Memoria en que el gobierno del estado libre de México da cuenta de los ramos de su administración al Congreso del mismo estado a consecuencia de su decreto de 16 de diciembre de 1825, impreso por orden del Congreso, México, Imprenta a cargo de Rivera, calle de las Capuchinas, p. 14; Memoria en que el gobierno del estado libre de México, da cuenta al segundo Congreso Constitucional, de todos los ramos que han sido a su cargo en el año económico corrido desde 16 de octubre de 1828, hasta el15 de igual mes de 1829. Presentada el día 20 de marzo de 1829. Se imprime del orden del mismo honorable Congreso, Imprenta del Gobierno del Estado libre de México a cargo de Juan Matute González, pp. 1-2. 6 Libertad, 24 de enero de 1879; La Ilustración Católica, 31 de enero de 1879. El Siglo Diez y Nueve, 30 de enero, 10 de febrero, 14 de agosto de 1877; El Monitor Republicano, 15 de febrero de 1877. Era tal el estado de pobreza que éstos periódicos advirtieron que "Hoy no caben los enfermos en los hospitales, ni en las casas de beneficencia los pobres, y 
Algunos pensadores de la época atribuyeron la falta de empleos a otros factores. Por ejemplo, se analizaron consecuencias que traía consigo el proceso de industrialización, así como la libre importación de mercancías: "La libre importación de mercancías de los efectos extranjeros, es la causa de la miseria en que se encuentra nuestro pueblo tiempo hace". 7 Mas tarde, los intelectuales liberales y los católicos empeñaron esfuerzos en formular un pensamiento social que permitiera explicar la pobreza y sus efectos más visibles. Ambos grupos de intelectuales coincidieron en señalar que la pobreza tenía su fundamento en razones más terrenales que divinas: era un acto individual y voluntario, ya fuese porque no hubiera la intención o móviles de mejoramiento social y económico o bien porque se elegían actividades $\mathrm{u}$ ocupaciones que sin ser consideradas honorables si permitían una vida de holgura y comodidad.

Para finales del siglo XIX, bajo el influjo del pensamiento positivista, se buscaron explicaciones en otros factores tales como la herencia biológica o los atavismos culturales y sociales. ${ }^{8}$ En el centro de esa idea se colocó al individuo, el cual tenía obligaciones y deberes que según los observara podían redituarle estabilidad y mejoramiento económico y social. La clave de su ascenso social estaba en el trabajo honrado, la sobriedad, el ahorro, en una palabra la vida austera. ${ }^{9}$

Junto a tales representaciones sociales y estados de ánimo se efectuó un lento proceso de estudio y clasificación de los pobres que, a su vez, sirvió de apoyo para diseñar una política de control, persecución y atención social, en especial de los llamados vagos y malentretenidos a fin de encerrarlos, inmovilizarlos y corregirlos, "apagando el bullicio de la fiesta con gruesos muros". 10

los fondos públicos no bastan para aliviar a los innumerables que llaman a las puertas de la caridad pública”.

7 Monitor Republicano, 16 de enero; 1 de septiembre de 1877.T

8 González Navarro, Moisés. La pobreza en México, México, El Colegio de México, 1985, pp. 37-41; 56-57.

9 Véase Guerrero, Julio. La génesis del crimen en México, París, Librería de la V. de Ch. Bouret, 1901; López Portillo y Rojas, José. Escritos económicos, México, Tipografía de El Tiempo, 1910.

10 Alvarez-Uría, Fernando. Miserables y locos. Medicina mental y orden social en la España del siglo XIX, México, Tusquets, pp. 33-40; Padilla Arroyo, Antonio. El sistema educativo y la beneficencia en el estado de México 1867-1910, México, ISCEEM, 1993, pp. 4-5. La idea de la reforma social y moral estuvo presente en prácticamente todos los escritores mexicanos del siglo XIX. En general, coincidieron en señalar que esta tenía como objetivo introducir nuevos hábitos, costumbres y actitudes que se adquirirían por medio de la instrucción. La 
La manifestación de nueva organización social obligó a reformular el control social. Un ejemplo de esa preocupación social, así como de la presencia de nuevos grupos fue un decreto expedido en 1839 por las autoridades federales, que además de ser un documento sumamente interesante porque marca las líneas de continuidad en este asunto entre las autoridades ilustradas y la élite política mexicana, para perseguir y castigar la vagancia. En ese decreto se definía a una amplísima variedad de vagos y de actitudes que podían tipificarse como vagancia. Prácticamente a lo largo del siglo XIX se mantuvo dicha definición, además de anticipar, en términos generales, las diversas instituciones que debían fundarse de acuerdo con el tipo de sujeto a quien se sancionaba. Así, vagos eran aquellos que "sin oficio ni beneficio" no podían justificar un modo honesto de vida, los hijos de familia que visitaban con regularidad las casas de juego y se hacían acompañar de individuos "mal opinados" o no podían demostrar un empleo. Incluía a los jóvenes que, por descuido de los padres o por su orfandad, se convertían "en forasteros en los pueblos" o bien en "prófugos sin destino". Al carecer de crianza se perdían "en el camino de la ociosidad voluntaria" y se dedicaban a pedir limosna. Dentro de esta definición también se encontraban quienes no asumían obligaciones con su casa, "sin visible motivo" daban mala vida a su mujer y se dedicaban a escandalizar y adquirir "malas costumbres", entre las que se tipificaban como tales el amancebamiento, el juego, la embriaguez, las rondas, la música y los bailes "en los tiempos y modos que la costumbre permitida no autoriza ni son regulares para la honrosa recreación”. Asimismo, incluía a quienes tenían un oficio pero no lo ejercían "lo mas del año", al jornalero que "trabaja un día, lo deja de hacer muchos" y se daba a la ociosidad "sin la aplicación a los muchos que puede ayudarse”. El decreto atajaba cualquier pretexto sobre su permanencia en la ciudad, el campo, las haciendas y los pueblos, advirtiendo que "no existía la excusa de las inundaciones o la escasez de tierra porque podía dedicarse a trabajos familiares que "toda la gente del campo entiende". De igual manera, el aspecto físico era un criterio definitorio: una presencia sana, vigorosa y robusta o con lesiones que no impidieran dedicarse a una ocupación y que anduviera de “puerta en puerta pidiendo limosna” podía ser suficiente para ser reputado de vago y malentretenido. A esta larga lista se sumaban una serie de oficios como gaiteros, bolicheros, saltimbanquis, los que andaban de pueblo en pueblo con máquinas reales, linternas mágicas, perros y “otros animales amaestrados”, así como aquellos que se ocupaban de actividades que "no valiendo todas ellas lo

capacitación para el trabajo, el ahorro, el afán de mejoramiento social, el esfuerzo individual, los derechos y obligaciones del ciudadano, fueron considerados los principales valores que debían inculcárseles, de acuerdo con los requerimientos de una sociedad moderna e ilustrada. 
que necesita el vendedor para mantenerse ocho días", servían para inclinar a los jóvenes a separarse de sus casas mediante el engaño o la estafa.

La amplia gama de conductas y ocupaciones que normaba este decreto tuvo la finalidad de ejercer un mayor control y vigilancia sobre un sector de la población que por su forma de vida resultaban difícil de sujetar a la nueva moral que demandaba la élite. La pobreza festiva y danzarina fue muy pronto considerada peligrosa, antiinmoral, poco rentable y asociada a las plagas que distinguían a los cuatro jinetes del Apocalipsis. ${ }^{11}$ En el extremo de la pobreza se encontraba la mendicidad, que fue tasada bajo el criterio utilitarista al atribuirle un móvil de cálculo racional, como cualquier otra profesión lucrativa. Esta fue considerada la "verdadera plaga de nuestra sociedad". No pocos escritores hicieron notar, a veces con tono dramático y en otras ocasiones con repulsión, las consecuencias más nocivas de la mendicidad, en especial de la infantil. La pobreza campeaba en todo el país, en especial en las ciudades, convertidas en el principal foco de corrupción moral y desorganización social. En especial la ciudad de México se había convertido en una "ciudad de mendigos", cubierta en su superficie de una "capa dorada”, aunque debajo de ella se descubrieran las "miserias más asquerosas".

La elaboración de tipologías sociales que permitieran distinguir, diferenciar y separar diversas clases de pobres y fundar instituciones de atención para cada uno de los grupos de pobres introdujo el criterio económico en las tipologías sociales, que desplazó el factor moral o ético de clasificación social, al tiempo que la sociedad moderna se abría paso. Una línea crítica se estableció entre los "pobres dignos" o clases trabajadoras y los "pobres indignos" o clases andrajosas, entre quienes estaban imposibilitados para el trabajo y quienes hacían de esa actividad un negocio. La degradación moral y social de sectores importantes de las "clases menesterosas" debido a su estado de miseria se agravaba por la falta de instrucción y enseñanza, la cual posibilitaba que se moralizaran, es decir, se educaran y adquirieran el amor por el trabajo. ${ }^{12}$

11 Archivo Histórico del Estado de México (AHEM), caja 003, 1839, volumen 19, exp. 24. "Real orden de 30 de abril de 1745 sobre vagos que cita el art. 6o del decreto del Estado de 23 de septiembre de 824 y el mismo que arregla los reemplazos del Ejército permanente, 839”; Alvarez-Uría, Ob. cit, p. 40.

12 El Monitor Republicano, 16 de enero de 1877; El Siglo Diez y Nueve, 21 de agosto de 1877. La metáfora de una plaga que se extiende por el país fue muy similar a la descrita por un escritor francés en el siglo xviii para referirse a un problema semejante. En este caso se trataba de una plaga de langostas que se abatía sobre la campiña francesa: "Son insectos voraces que destruyen cotidianamente la subsistencia de los labradores. Son para hablar sin metáforas, tropas enemigas diseminadas sobre la superficie del territorio, que viven sobre 
Particularmente los vagos fueron diferenciados en tres categorías, lo cual demostraba un mayor conocimiento de las condiciones económicas y sociales en las que se desenvolvía: necesarios, aquellos que no trabajaban "por falta absoluta de trabajo", los voluntarios, que no laboraban porque no lo deseaban, sin que por esto cometieran acciones que dañaran a la sociedad o perjudicaran a terceros y los perniciosos, que no sólo no trabajaban, sino que cometían acciones que ofendían a la moral o perjudicaban a la sociedad. Estos últimos eran asiduos parroquianos de lupanares, pulquerías, vinaterías, billares y tabernas que se dedicaban a embriagarse o se ocupaban en "fraguar delitos". En sentido estricto, no eran individuos dedicados a la delincuencia sino personas que asumían una función antisocial, antieconómica, incómoda y desagradable, es decir, atentaban contra la moral que se procuraba difundir. ${ }^{13}$

Para éstos se recomendaba el trabajo y la instrucción como los instrumentos de moralización, símbolo del éxito y del bienestar social. Por ejemplo, en una colaboración enviada a El Monitor Republicano, se puso el acento en la "plaga de todas clases y edades de los dos sexos" para explicar que si bien la mendicidad y la vagancia no podían juzgarse como actividades criminales o ilícitas, si predisponían a ellas en la medida que provocaba el libre juego de la imaginación y la meditación de los crímenes. De ahí a su ejecución no había más que un paso. El colaborador sostenía que "el único antídoto especial" para prevenir tales actividades era inculcar en esos individuos el amor al trabajo al tenerlos "en entretenimiento en objeto determinado", evitando que cayeran en cualquier tentación y, por tanto, que hicieran daño a la sociedad debido a las funciones sociales que desempeñaban en los bajos fondos de la sociedad mexicana: espía, encubridor de criminales o seductor de la joven y la mujer casada. ${ }^{14}$

\section{Reformar y Moralizar}

En este marco se propuso emprender de inmediato una profunda reforma social entre las clases menesterosas capaz de inculcar nuevas conductas, usos y costumbres a fin de preservar el orden y la estabilidad social que con grandes esfuerzos se estaba edificando, en la medida que la existencia de esos grupos sociales se percibió como una amenaza potencial. Esa reforma debía completarse con la reorganización de las instituciones tradicionalmente destinadas

él a discreción como en país conquistado y que imponen contribuciones con el título de limosna”. Véase Foucault, Michel, Vigilar y castigar, México, siglo XXI, 1981, p. 81.

13 Gaceta de Policía, 13 de febrero de 1867

14 I Monitor Republicano, 16 de marzo de 1877. 
a la atención de los pobres, redefinir sus fines y medios para cumplir con el nuevo papel que exigía el nuevo orden social. ${ }^{15}$

Entretanto surgió una generación de reformadores sociales que propusieron una serie de mejoras en las instituciones destinadas a la atención social de los pobres. Este esfuerzo reformista se acompañó de una nueva concepción del modelo y del tipo de hombre que debía forjarse en esos establecimientos, después de tener la certidumbre de su regeneración: trabajo, educación, religión y amor serían la base de la meta- morfosis social e individual que los sacaría de la degradación, la miseria y el vicio. Estos reformadores estaban convencidos de modificar algunos atavismos culturales o biológicos, en una visión optimista del progreso y la civilización como fuente de redención social, y de persuadir a los pobres para soportar su situación, abandonar su vida de disipación o criminalidad, así como a aprender a valorar las virtudes y habilidades del trabajo honesto para hacerse mejores hombres. Se intentaba diseñar un modelo de hombre, que tenía mucha similitud con el ideal del hombre protestante, puritano, de "hombres ilustrados" en que el trabajo y estudio fueron las bases de su formación y obtuvieran como recompensa el bienestar personal. ${ }^{16}$

En gran medida, la Iglesia católica contribuyó al proceso de secularización de la pobreza. Un ejemplo de ello fue la colaboración que prestó a las autoridades para recabar fondos y estadísticas que permitieran edificar hospitales, hospicios, socorrer viudas, poner casas de mujeres arrepentidas, criar huérfanos y niños expósitos y levantar otros establecimientos para atender a los pobres. Se buscaba introducir la visión moral y social de las autoridades concernientes a la pobreza. Desde una ética puritana y rentabilizadora se reprochó a los pobres sus excesos, se acentuaron los supuestos o reales factores negativos que encerraba y se condenaron sus excesos: inmoralidad,

15 La tesis del nuevo orden social no fue del todo clara entre la élite política mexicana Durante gran parte del siglo xix dicha noción estuvo vinculada con la presencia de la sociedad colonial, la cual se asociaba a la concentración de la tierra, el predominio de la Iglesia sobre una masa ignorante y supersticiosa, el privilegio de los españoles en actividades productivas y en la falta de movilidad social entre los razas, así como el dominio de los gremios sobre las más importantes ocupaciones industriales. Por tanto, el nuevo orden social estaría basado en el impulso a nuevas actividades lucrativas, que dotarán a los "ciudadanos" de incentivos para mejorar su situación y, por añadidura, del conjunto de la sociedad. Así, la gran tarea era edificar un nuevo orden donde prevalecieran los principios de libertad e igualdad, la separación del Estado y de la Iglesia, la libre movilidad de la propiedad y de los individuos. La secularización de la vida social.

16 Gaceta de Policía, 13 de febrero de 1867. 
holgazanería, irreligiosidad, libertinaje y, en caso extremo, la rebelión. Entre los resultados de dicho tránsito estuvo la redefinición de los fines de las instituciones sociales que se orientaban a la atención de los pobres. Esas instituciones pasaron de simples sitios de auxilio espiritual o de refugio y recogimiento a espacios de coacción y, en muchas ocasiones, de acción educativa entre los pobres. El propósito fundamental fue instruirlos "en los rudimentos de nuestra Santa Fe, (y) quitarlos de la ociosidad” porque en ella se gestaban gran parte de las conductas antisociales y la perversión de las costumbres, lo cual los volvía en enemigos de la república. En esos establecimientos se proyectó una nueva racionalidad, que revelaba un optimismo desbordante, basada en las supuestas bondades que ofrecía la educación para producir en los pobres una profunda transformación social. Lograr que el mayor número de pobres recibieran instrucción era visto como una garantía de forjar buenos ciudadanos y fue uno de los objetivos inclaudicables de la élite política que permeó el pensamiento educativo durante el siglo XIX. En 1868, por ejemplo, se creía invariablemente en que la instrucción podía garantizar un cambio en las mentalidades de las clases pobres y así lo manifestaba el periódico oficial del estado de México, La Ley. En un editorial apuntaba: "La instrucción de las masas es la que determina el bienestar y felicidad, el niño que se acostumbra a prestar obediencia a las autoridades emanadas de gobiernos legítimos y justos será un buen ciudadano, buen padre de familia y buen cuidador de las leyes, y si se deja en la ignorancia, será un hombre contra la sociedad y de su bienestar, asesino y pendenciero, trastornador del orden y todo por no inculcarle los preceptos de la moral y el conocimiento de sus obligaciones civiles". ${ }^{17}$

La diferenciación de los grados de pobreza y de los grupos de pobres tuvo entre sus propósitos reconocer quienes eran el eje de dicha reforma y destinar algunos establecimientos de la beneficencia pública y privada a tal fin. Los primeros serían enviados a los hospitales y casa de asilo, mientras que para los segundos los talleres del hospicio, las casas correccionales o, en última instancia, la cárcel donde se les daría ocupación en actividades productivas porque era urgente "cambiarlos, moralizarlos por medio del trabajo". ${ }^{18}$

Uno de los más activos difusores de la reforma social, José María Castillo Velasco, a la sazón presidente del Tribunal Superior de Justicia del Distrito Federal, estaba plenamente persuadido que dicha reforma tenía que procurar una renovación de las costumbres y hábitos, haciendo de la moralización y 17 Tanck de Estrada, Dorothy, La educación ilustrada 1786-1836. Educación primaria en la ciudad de México, México, El Colegio de México, 1984, pp. 114-115; Stopes, Anne. "Alfabeto y catecismo, salvación del nuevo país" en Historia Mexicana, México, El Colegio de México, julio-septiembre 1979, núm. 1; La Ley, 13 de marzo de 1868.

18 El Monitor Republicano, 23 y 24 de marzo de 1877. 
la instrucción el eje de la misma. Al presentar un informe al Congreso de la Unión sobre su propuesta destacó que el mayor número de presos y encauzados pertenecían a la "clase Ínfima del pueblo", quienes carecían de arte, oficio y educación. Entre ellos sobresalían peones de todas clases y jornaleros del campo. Después le seguían los ocupados en oficios y artes "que no exigen el desarrollo de una gran fuerza muscular, sino un trabajo sedentario": zapateros, sastres, tejedores y otros. En un grado superior en la escala de la criminalidad se hallaban los carpinteros y curtidores y, ocasionalmente, "los hombres que se ocupan de ciertas labores que los ponen en contacto con las clases de la sociedad, superiores en educación": plateros, ebanistas, impresores y cajistas. Para Castillo Velasco, el factor fundamental de las conductas antisociales residía en la falta de instrucción y educación, más que en factores económicos o sociales, porque aquellas enseñaban a "dominar las pasiones". Por ello urgió a las autoridades a "llevar los beneficios de la educación a esos desgraciados jornaleros y a todas las clases de la sociedad que carecen de ella". Una clase aparte eran los indígenas, quienes también carecían de instrucción, pero el índice de criminalidad entre ellos era menor porque "diariamente agotan sus fuerzas en el trabajo y tienen menos ocasión de delinquir". La educación que les fuese impartida tendría otro tipo de beneficios en tanto les mostraría las ventajas de la producción y el consumo del mercado nacional. En fin, la escuela inculcaría entre las clases menesterosas "nuevos hábitos, nuevas necesidades, nuevas costumbres" y evitaría "en ciertas esferas de la sociedad muchos delitos, en particular los robos". ${ }^{19}$ En este sentido, el gobernador Muzquiz un ambicioso proyecto que abarcaba la amplia difusión de establecimientos educativos, la creación de juntas de beneficencia en todo el territorio presididas por hombres y señoras de la alta sociedad y un programa para dar ocupación "útil y productiva" a un sector de la población que se encontraba en una condición miserable, debido, según él, a los vicios de su "organización física o moral", la cual los obligaba a "mendigar su sustento". Entre sus propuestas estaba la posibilidad de reformar el Hospicio de Pobres, ubicado en la ciudad de Tlalpam ${ }^{20}$

19 El Monitor Republicano, 28 de julio, 23 y 24 de mayo de 1877. En opinión de Mellosi y Pavarini, el móvil principal de la fundación de los establecimientos de beneficencia, en particular las orientadas a funciones pedagógicas y reeducativas, fue sostener una tendencia a recuperar Y reeducar a los niños y jóvenes, en especial éstos últimos, por ser fácilmente corregibles, dóciles y resistentes para incorporarse al mundo del trabajo, Ello explica porque los casas correccionales fueron acompañadas de escuelas profesionales, orfanatorios, etcétera, Mellosi, Dario y Pavarini, Massimo, Cárcel y fábrica, Los origenes del sistema penitenciario (siglos XVI-XIX), México, Siglo XXI Editores, 1980, pp.,100-101.

20 Memoria, 1826, p, 6, 
Convergencia Revista de Ciencias Sociales, núm. 8/9, 1995, Universidad Autónoma del Estado de México

\section{El Aparato Institucional}

La diferenciación entre los pobres creo también una distinción entre las instituciones destinadas a su atención con distintos medios y fines. Unas se destinaron a la prevención de las conductas antisociales, entre ellas la prostitución, la vagancia y la mendicidad, en tanto otras a reprimir las conductas ilícitas o crimina- les. Las primeras quedaron a cargo de la beneficencia pública y privada y las segundas se reservaron a la vigilancia estatal, en particular, las instituciones carcelarias y correccionales. Ambas tendrían por objetivo central el control social, entre otros aspectos, mediante la educación a fin de evitar los efectos más indeseables de ambas conductas. De esos establecimientos saldría "un ser moral" con nociones del bien" ensanchando en este efecto los límites de la inteligencia y los buenos sentimientos del corazón".

Las primeras orientarían su labor hacia las "clases más desprotegidas" con el objetivo de prevenir lo que tanto temía la élite gobernante, al cerrar el círculo de la lógica de esos institutos: la pobreza como posibilidad de acciones antisociales, que podían poner en peligro el orden social y, por ende, necesidad de construir sitios que mitigaran la conflictividad social, regular los conflictos y tensiones del crecimiento eco- nómico y finalmente, forjar un nuevo hombre.

Entre sus finalidades estaban hacer hombres útiles, sin hacerlos sentir que se les confinaba, crear de talleres con la obligación de restituir a la sociedad el costo de su capacitación y estancia, pues la existencia de esas instituciones no debían juzgarse como concesiones gratuitas porque la experiencia había demostrado que cuando la caridad, la filantropía y la beneficencia se ofrecía sin ningún compromiso se fomentaba la ociosidad y la holgazanería. ${ }^{21}$

Uno de los estudios más acucioso s en este campo fue el presentado por Justino Fernández Castelló. Para éste autor, la pobreza tenía diferentes motivos y causas. Por ello era indispensable analizarla para, a su vez, formular diversos medios para prevenirla y aliviarla. Esos motivos o causas podían ser por completo ajenas a la voluntad de los individuos: epidemias, inundaciones, despidos y otros elementos eran ajenos a cualquier cálculo. Criticaba a aquellos que pensaban que la pobreza y la miseria se reducían a una "falta de espíritu de previsión" o que eran las leyes naturales las que hacían aptos o ineptos a los hombres. Sin embargo, no negaba la desigualdad social, pero

21 García Icazbalceta, Joaquín. Infom le sobre establecimientos de beneficencia y corrección de esta capital, su estado actual, noticia de sus fondos, que desde luego necesitan y plan general de su arreglo presentado por José María Andrade. Escrito póstumo de..., México, Moderna Librería Religiosa, 1907. 
un hecho era admitirla y otra muy distinta sostener "el bárbaro principio de la selección”, el cual eliminaba a los pobres, a los niños, a los ancianos, a los enfermos y, por ende, desconocía los sentimientos humanitarios. ${ }^{22}$

La "beneficencia científica" era por tanto útil, necesaria e imprescindible para esos casos. Esa beneficencia reconocía cuatro niveles de pobreza: aquella cuyo origen fuera el nacimiento o un accidente. Los sordomudos, los ciegos, los paralíticos o el deceso del jefe de familia; quienes padecían condiciones sociales adversas, "casos pasajeros que son la consecuencia de ciertos cambios generales verificados en el seno industrial de una sociedad", los desplazados por la introducción de tecnología y de modificaciones en la división del trabajo. La ayuda que se les brindaría tendría un carácter perentorio y sería un complemento de la previsión, es decir, de las cajas de ahorro, las sociedades mutualistas, las cooperativas; el tercero, atendería a las víctimas de las costumbres y los vicios de sus padres, quienes fomentaban la mendicidad como un medio de lucro, así como la vagancia. Estos formaban el contingente del "pauperismo, es decir, la miseria hereditaria". La beneficencia se cuidaría de promover el vicio y la degradación social y "arrancar el foco degradante $\mathrm{Y}$ envilecedor en que viven", en especial los niños; en cuarto nivel lo integraban aquellos "débiles morales o intelectuales" producto de sus vicios, de la imprevisión, de la vagancia, de la glotonería y del alcoholismo. Para ese sector la beneficencia no tenía ninguna obligación porque ponía "un freno al vicio fomentando, a su vez, el sentido de previsión”. El tratamiento adecuado y juicioso en cada uno de esos niveles permitiría al estado y la sociedad guardarse en contra de quienes juzgaran que su situación era resultado de la dureza de la sociedad y evitaría "que adoptaran la teoría de que fuese necesario un cambio en el orden social".23

En resumen, la función de esas instituciones era prevenir los crímenes y evitar la proliferación de los delincuentes. Mediante la disciplina y el trabajo se procuraría que los inquilinos "comprendan que (en) nuestra época es difícil

22 Fernández Castelló, Justino. Las fundaciones de beneficencia privada bajo su aspecto económico y jurídico, México, Tip. y Lit. y Encuadernación de Irineo Paz, 1897, pp. 13-70.

23 Ibid; González Navarro, Moisés. Vida social, t. iv, 1957, p. 518. Entre ambas posiciones había una serie de matices. Por ejemplo, hubo quienes reconocían la importancia de la beneficencia, pero criticaban la excesiva intervención del estado en este punto. Sostenían, en el más puro estilo liberal de la época, que no era ni atribución, ni obligación estatal intervenir en un campo reservado exclusivamente a los particulares. En todo caso, el estado tenía la facultad de reglamentar la organización y el funcionamiento de los establecimientos de beneficencia. Este era el punto de vista de jurista Miguel Macedo. 
abrirse paso cuando no se lleva un caudal de conocimientos para vencer las dificulta- des que a menudo impiden la marcha del hombre", así como modificar el carácter, evitar los extravíos y perderse en pasiones insanas". ${ }^{24}$

Para los primeros estaban reservadas las casas de niños expósitos, las escuelas correccionales o las industriales a fin de proveerlos de algún oficio e instrucción, mientras que para los segundos las casas de asilo o los hospitales. Para los adultos, cuya edad fluctuaba entre los 16 y 54 años, los trabajos forzados, las tareas de limpia o la leva. ${ }^{25}$ Finalmente, la cárcel si se demostraba su peligrosidad o se comprobaba que el detenido era reincidente de delitos menores. ${ }^{26}$

$\mathrm{Al}$ iniciarse el porfiriato, tanto las instituciones dedicadas a la prevención como las dedicadas a la represión de las conductas antisociales y criminales se encontraban en un estado que causaba espanto y repugnancia a quienes las visitaban, al igual que el provocado por las "cuadrillas de léperos sucios y perdidas greñudas" o los batallones de pillos en cafés, teatros, calles y templos, formando la "cofradía inmoral de la limosna callejera". ${ }^{27}$

El conocimiento de los habitantes de aquellas instituciones pronto les reveló una realidad más dramática e atroz: el trato inhumano que recibían los habitantes de las cárceles, asilos, hospitales, escuelas de artes y oficios, escuelas industriales, hospicios, etcétera. La tarea que se echaron a cuestas fue prácticamente irresoluble:"Cada reforma era una respuesta a un problema que pedía a gritos una reforma; cada expresión de compasión y cada reacción eran provocadas por una evidencia inequívoca de miseria y vicio" ${ }^{28}$ Los

24 Peza, Juan de Dios. La beneficencia en México, México, Imprenta de Francisco Díaz de León, 1881, pp. 165-166.

25 Ibid; González Navarro, Moisés. Anatomía del poder en México, México, El Colegio de México, 1977, pp. 176-195.

26 Archivo Histórico de la ciudad de México (AHCM), Ramo Vagos, exps. 428, 515,540; 1867.

27 Urbina, Luis G. Crónicas, México, Editorial Universitaria, 1946. pp. 19-20.

28 Himmelfarb, Gertrude. La idea de la pobreza. Inglaterra a principios de la era industrial, México, Fondo de Cultura Económica, 1988, p. 324. En 1871, Antonio Martínez de Castro, responsable de la comisión encargada de elaborar el Código Penal para el Distrito y Territorios Federales, primero en su especie en México, resumió la situación lamentable de las cárceles del Distrito Federal: "En ellas ven aglomerados, confundidos y en completa comunicación personas de todas las edades: el ladrón ratero y el salteador en cuadrilla, el reo de simple riña y el asesino, el hombre honrado que, en un momento de pasión o ceguedad cometió una ligera falta y el facineroso, los criminales ya condenados y los inocentes a quienes se esta procesando. Entregados todos ellos a una absoluta ociosidad, son actores o testigos de las escenas más vergonzosas y repugnantes, y no escuchan sino el relato de espantosos crímenes, 
edificios se encontraban en pésimas condiciones materiales y quienes se aventuraban a pisar esos espacios, habitaban galerías inmundas, padecían los efectos de la aglomeración y el consiguiente riesgo de contraer o provocar epidemias que los diezmaban, en un ambiente de corrupción y desorganización administrativa que favorecía el deterioro de sus condiciones de vida. Pero ello no impidió proponer soluciones a los problemas que representaban provenían de empresarios y filántropos que mostraban preocupación por esas instituciones.

El tema de la reforma institucional y social, los obstáculos, las condiciones de los edificios y de los huéspedes, la falta de recursos para financiar los trabajos que exigían la construcción de edificios modernos y funcionales, las consecuencias de las continuas asonadas y el empleo de los reos como fuerza militar fueron punto de reflexión de algunos gobernantes, quienes veían en él el reflejo de los males del país y de la urgencia de repensarlo sobre nuevas bases, es decir, sobre la estabilidad política y el crecimiento económico, del orden y el progreso. También manifestaba una inquietud más profunda, la cual tenía relación con la idea del tránsito de la barbarie a la civilización ${ }^{29}$

Las cárceles y los huéspedes de ellas demostraron la profundidad de la reforma que debía emprenderse. No obstante, los reformadores enfrentaban un efecto indeseable cuando emprendían o promovían las reformas en esas instituciones: cómo disuadir a quienes se dedicaban a delinquir a mudar su forma de vida por el trabajo honrado, al indigente para inducirlo a aprovechar las ventajas de la ayuda y el trabajo, al preso evitar el placer de una vida cómoda al tener garantizado la comida y el sustento además de representar una carga para su familia en comparación con las penalidades del trabajo regular y honrado. En medio de esta realidad contradictoria, había que evitar que la condición de los huéspedes de los establecimientos de beneficencia y las carcelarias fuera preferible a la de las clases trabajadoras. ${ }^{30}$

o los planes y proyectos de otros nuevos. Allí no hay más títulos a la consideración que la desvergüenza, el derecho, la osadía; y aquellas turbas de malvados se complacen en hacer víctimas de su brutalidad, y en arrancar todo sentimiento de honor y de virtud a los que no están corrompidos como ellos". Martines de Castro, Antonio. "Exposición de motivos del Código Penal en el Distrito Federal y Territorios de Baja California” en Criminalia, año XXXIV, núm. 3, 30 de marzo de 1968, p. 152

29 Macedo, Miguel. "El municipio. Los establecimientos penales. La asistencia pública” en Justo Sierra, México, su evolución social, México, J. Ballesca, 1902, t. 1, vol. 2, pp. 665-724.

30 Las autoridades de la ciudad de México estaban concientes de este inconveniente. En 1873, el gobernador del Distrito Federal, Tiburcio Montiel sostenía que la alimentación que recibían los presos de las cárceles de la entidad eran de mucho mejor calidad que la que consumía el vecindario y agregaba que, en general, la estancia en esos sitios no era tan mala 
La reforma institucional y social vino precedida por significativos intentos para ajustar las instituciones a las nuevas condiciones del país. El impulso definitivo se produjo bajo las administraciones de Porfirio Díaz, en las cuales se recogieron las suficientes antecedentes sobre las ideas y los modelos de atención social a los pobres que se habían intentado, sin éxito, en diversas épocas en el país. Además, en este periodo se dieron las condiciones más propicias para ello: el país había entrado en una etapa de relativa estabilidad política, con la presencia de una institución capaz de asumir como una de sus obligaciones la atención y el cuidado de las prisiones mexicanas en la medida en que estas era uno de los mecanismos para garantizar el orden y la seguridad. En suma, la élite política estaba compro-metida en la reorganización el conjunto de los aparatos de control social.

\section{La Reforma y la Educación Penitenciaria}

En tanto, en forma paralela, se promovió la reforma penitenciaria y con ella la educación penitenciaria enmarcada en un proceso de mayor amplitud que incluía asilos, casas de corrección, escuelas de artes y oficios, casas de expósitos $y$, en general, las instituciones de beneficencia. Las instituciones de control social se diseñaron, en gran medida, para mitigar los efectos que provocaban los desajustes económicos y sociales del "industrialismo" entre grandes sectores de la población y que se reflejaban en un incremento de la vagancia, la mendicidad y la delincuencia. Esos establecimientos fueron concebidos, en parte, como centros de enseñanza fabril y de aprendizaje de nuevos hábitos, costumbres, actitudes y conductas más acordes a las necesidades de una economía en expansión. En ellos se proyectaba y se ejercitaba un esquema pedagógico tenía como eje inculcar la disciplina, los valores del orden social y el respeto a la propiedad privada. En una palabra, su propósito era forjar un trabajador ideal, corregir conductas calificadas de antisociales y capacitar para el trabajo. Para ello, sostenían los promotores de la reforma penitenciaria era necesario y posible la creación de espacios de segregación. Las cárceles y penitenciarías siguieron un patrón similar de organización y funcionamiento a

\footnotetext{
"sobre todo si se tiene en cuenta la vida miserable del pueblo en general, pues en la calle no comen sino tortillas y casi nunca carne”. Asimismo, en 1881, el entonces gobernador del Distrito Federal, Ramón Fernández advirtió que la cárcel debía considerar un sistema de castigo riguroso para evitar "que el establecimiento (sea) un lugar atractivo o de tentación, un refugio atractivo e irresistible". Memoria del Ayuntamiento, 1878; Montiel citado en Novo, Salvador, Un año hace ciento. La ciudad de México en 1873, México, Editorial Porrúa, 1973; Diario Oficial, 18 de agosto de 1881, núm. 196.
} 
las instituciones educativas, aunque la diferencia básica fue la privación de la libertad y la segregación total. Aquellos establecimientos fueron proyectados como el modelo de institución de control social. Así, por ejemplo, se sistematizó un método de premios y castigos, se suprimieron formalmente los castigos físicos, mientras que el régimen de inspección y vigilancia se hizo más sutil a fin de que el preso no tuviera "jamás la seguridad de no estar vigilado o de no poder ser sorprendido” y la observación se personalizó, ordenándose un control riguroso sobre sus movimientos y relaciones. Todo ello pretendía completarse con la enseñanza religiosa, al cuidado de sacerdotes reconocidos y "bien conceptuados", la instrucción y la capa- citación laboral. ${ }^{31}$ Para los reformadores su propuesta no provenía de inspiraciones metafísicas o de especulaciones. Su modelo carcelario tenía su referente en el funcionamiento y organización de la sociedad:

"La semejanza de la constitución de la penitenciaría con la de la sociedad; debe enseñar al preso, que en esta lo mismo que en aquella, el medio de obtener el bienestar y la felicidad es la honradez, y que el camino del vicio lleva al dolor y termina en el infortunio. Inculcar esta idea en el preso, hacer que en su espiritu se restablezca una robusta y firme asociación es el medio más eficaz para hacerle adoptar el buen camino..."32

La reorganización penitenciaria atrajo la atención de algunos escritores de la época. Por ejemplo, en 1828, el gobernador Lorenzo de Zavala advirtió de los graves inconvenientes que representaba el sistema penal heredado de la Colonia y criticaba duramente las penas más comunes de la época porque en su opinión la pena de presidio, que era la más usual en esos años, había demostrado su ineficacia y su crueldad. Agrega que mantener vigente esa pena, como después se juzgaría con severidad la privación de la libertad, era condenar a los presos a la muerte, es decir, era un castigo similar a la pena de muerte, pues no era otra cosa el envió de los presidiarios a climas insalubres. Además tal castigo no traía ningún tipo de beneficio a la sociedad pues existía el peligro siempre inminente de las fugas o los malos tratos de los custodios.

En suma, opinaba Zavala, la pena de presidio lo único que provocaba era que los criminales regresaran, si lograban sobrevivir a las duras condiciones de castigo, más depravados y volvieran a "infestar a la sociedad con sus crímenes". Para el gobernador el objetivo de la cualquier pena no era exterminar a los delincuentes sino corregirlos y aterrarlos con penas ejemplares. Así, vislumbraba ya el sentido que debe- rían tener las cárceles: evitar que se

31 AHCM, Ramo Cárceles, t. 501, exp. 707, 1878; 696, 1876; t. 502, exp. 701, 1880; Romero, Félix. El sistema penitenciario tratado por el lic. ..., México, Imprenta Moderna, 1897.

32 Boletín del Archivo General de la Nación, 1981-1982, Nos. 1/4, p. 26 
multiplicaran inútilmente los castigos, pero sobre todo mejorar "la condición moral de los hombres, a quienes la miseria o la violencia de sus pasiones ha precipitado en la carrera del crimen" ${ }^{33}$

En esta línea de reflexión, en 1844, el escritor y político jalisciense Mariano Otero afirmó que la "legislación criminal, es a la vez el fundamento y la prueba de las instituciones sociales". ${ }^{34}$ Las cárceles eran un signo de los tiempos, de los viejos y los nuevos, en los cuales se había formado la nación. En este sentido, desde los primeros empeños realizados por el patrocinador cultural Manuel Eduardo Gorostiza, fundador en 1843 de la Casa de Corrección para Jóvenes Delincuentes, hasta los esfuerzos del ingeniero Antonio Medina y Ormaechea y el primer director de la Penitenciaría del Distrito Federal Miguel Macedo las iniciativas sobre la renovación carcelaria provinieron de particulares. Tampoco faltaron planes sugerentes e imaginativos de altruistas, empresarios y comerciantes para brindar recursos con el objetivo de financiar la edificación de penitenciarías a cambio de concesiones federales de distinta índole, pero la ausencia de una organización estatal descentralizada y el permanente cambio de administraciones y la sucesivos regímenes políticos pronto desalentaron esas iniciativas debido al peligro de perder las prebendas gubernamentales.

$\mathrm{Al}$ mismo tiempo que se inició la reflexión sobre la orientación de la reforma y la educación penitenciaria, se llamó la atención sobre las pésimas condiciones de vida en las cárceles. Por ejemplo, en 1826, el gobernador del estado de México, Melchor Muzquiz, informaba de que en las cabeceras del partido había establecimientos carcelarios, pero todos ellos estaban en condiciones lamentables de higiene, no tenían empleados que las custodiaran y carecían totalmente de seguridad para evitar las fugas. Un par de años después Zavala urgió al congreso del estado a aprobar el presupuesto necesario

33 Memoria en que el gobierno del estado libre de México, da cuenta al primer Congreso Constitucional, de todos los ramos que han :;ido a su cargo en el año económico corrido desde 16 de octubre de 1826 hasta 15 de igual mes de 1827, presentada el día 13 de marzo de 1828 . Se imprime de orden del mismo honorable Congreso, Tlalpam, Imprenta del Gobierno a cargo de Juan Matute González, 1828, pp. 61-62.

34 Otero, Mariano. Obras del Lic..., México, Imprenta de Ignacio Otero, 1959. El sistema penitenciario de Filadelfia, instituido en 1790, se estructura conforme al aislamiento celular e individual de los reclusos con la obligación de guardar silencio, incomunicado a fin de meditar sus actos. Asimismo, prescribe la oración obligatoria. El diseño y funcionamiento se basaba en la idea de separar al reo y evitar el contacto con sus vecinos para evitar la promiscuidad e inhibir el factor criminógeno. Según estos principios, se inducía al reo a entrar en un proceso de introspección que se juzgaba el vehiculo más eficaz para su regeneración. Mellosi y Pavarini, 1980, pp. 170-172. 
para construir una "casa de corrección o penitenciaría" a fin de lograr que los criminales "en vez de embrutecerse y pervertirse" fueran un modelo de la adopción de los "hábitos saludables de la moderación y el trabajo". De hecho recomendaba el convento del Desierto, ubicado en el partido de Tenancingo, por sus circunstancias físicas y geográficas para ensayar "un experimento de esta clase" que podría conducir "a la solución de una de las cuestiones más importantes a la felicidad de los hombres". ${ }^{35}$

El siglo XIX fue un periodo de experimentación y maduración del régimen penitenciario y que concluyó con el porfiriato. El arribo al poder de Porfirio Díaz y el lapso de la administración de Manuel González, en donde se sentaron en definitiva las bases de la reforma carcelaria mexicana, significaron el fin de los esfuerzos individuales y que el Estado asumiera el proyecto penitenciario como una de sus tareas fundamentales, así como respuesta a la necesidad de una reforma penal que demandaban los sectores ricos y la élite gobernante.

En la década de los años cuarenta del siglo pasado varios intentos de reforma carcelaria se efectuaron. La cárcel de la ex Acordada, suprimida por las Cortes de Cádiz en 1812, se hizo célebre no sólo por el temor que inspiró entre sus habitantes, sino por las constantes denuncias de los intelectuales de la época que por distintos motivos se hospedaron en ella o por su inclinación a tratar este tipo de temas, lo cual originó importantes reflexiones sobre la necesidad de fundar el régimen penitenciario. Entre estos, destacaron el escritor y periodista Manuel Orozco y Berra, Manuel Payno y Mariano Otero. ${ }^{36}$

Este último realizó una profunda y meditada disertación sobre las condiciones materiales y humanas de esa prisión. A Otero le correspondió el mérito de haber propuesto en forma ordenada el sistema penitenciario y, tras de una larga reflexión, se pronunció en favor del modelo aplicado en las prisión norteamericana de Filadelfia, con el cual fue bautizado. El autor consideró la instauración de la penitenciaría como una contribución fundamental a la reforma social que la nación demandaba. ${ }^{37}$

Tanto Otero como Orozco y Berra denunciaron que la situación de las cárceles debía provocar vergüenza y repugnancia entre la sociedad mexicana, aunque el segundo se inclinó por el sistema Auburn porque se le consideraba más adecuado a la realidad del país debido a la organización carcelaria del trabajo que se establecía mediante el establecimiento de talleres, adaptándose a la organización artesana del país. ${ }^{38}$

35 Memoria, 1822, p. 23; Memoria, 1828, p. 62.

36 Mosaico Mexicano, 15 de febrero de 1844.

37 Mosaico Mexicano, 15 de febrero de 1844.

$38 \mathrm{El}$ sistema de Auburn funcionaba bajo otros principios: confinamiento solitario por la noche y trabajo común durante el día con la obligación de mantener el silencio entre los reos. 
Para Otero, el sistema penitenciario era la "adquisición más preciosa" de las instituciones modernas, que consistía en "la soledad que hace reflexionar, en el trabajo que doma las malas inclinaciones, en el aislamiento que preserva, en la instrucción que eleva, en la religión que moraliza y en el arrepentimiento que regenera”. Para ambos autores la prisión de la ex Acordada degradaba y envilecía al hombre "más por la manera de tratarlos que por sus crímenes".

En 1842, el primer esbozo de régimen penitenciario se formalizó con la fundación de la casa de corrección para jóvenes delincuentes. Para el Antonio Medina y Ormaechea dicha establecimiento fue el "primer germen de esa hermosa institución” en nuestro país. Otero destacó la labor de su promotor y filántropo José Gorostiza, pero lo juzgó insuficiente debido a la carencia de recursos para su sostenimiento, además de que no provenía del Estado encargado de su organización y funcionamiento. El único esfuerzo institucional que tuvo relativo éxito fue realizado por Otero con la penitenciaría de Jalisco y que concluyó en los primeros años del régimen porfirista. Esta experiencia puede considerarse con justicia el primer experimento en el lento proceso de formación del sistema penitenciario mexicano bajo el régimen de Auburn y que dejó su huella en distintos niveles de la administración carcelaria. A la par, se iniciaban los trabajos de la penitenciaría de Puebla.

Años después, en 1848, en la administración de José Joaquín Herrera, el Congreso de la Unión expidió una disposición titulada la "Ley Penitenciaria", la cual normaba, entre otras cosas, la forma de proveerse de recursos para la construcción de la moderna cárcel del Distrito Federal y Territorios. El sistema que se prescribía era el de Filadelfia. Un año después, tocó en turno al secretario de Justicia, Pascual González Fuentes, denunciar las pésimas condiciones que prevale- cían en las cárceles del estado de México y retomar la idea lanzada por Zavala de edificar cuanto antes una penitenciaría la cual se ubicaría en la capital del estado. En ella se crearían los departamentos para detenidos, sentenciados y niños huérfanos. La importancia de tal propuesta residía en que ahí los niños recibirían educación moral, artística y de primeras letras, mientras que los detenidos y sentenciados por vagos recibirían adiestramiento en trabajos útiles. Para los presos adultos la pena de presidio siguió siendo una constante. ${ }^{39}$

Según Pavarini, la introducción del trabajo común implicaba la posibilidad de transformar la cárcel en fábrica, además de introducir la obligatoriedad de la educación, la disciplina y modalidades de tratamiento y rehabilitación de los delincuentes. Mellosi y Pavarini, 1980, pp. 170-172.

39 González Fuentes, Pascual. Memoria de la Secretaría de Relaciones y Guerra; Justicia; Negocios Eclesiásticos e Instrucción Pública, citado en Ruelas García Roberto, et al, Modelo de Educación Penitenciaria. Estado de México, Toluca, Gobierno del Estado de México, 
En 1850, bajo los lineamientos de dicha ley, el arquitecto de origen español Lorenzo Hidalga presentó un proyecto de edificio carcelario. Sin embargo, no hubo ningún resultado concreto. Posteriormente, en 1853, José María Bellozi dio a conocer al gobierno del Distrito Federal su proyecto carcelario, pero fue rechazado por las autoridades respectivas, pues años antes la había sujetado al examen del Gobernador de Michoacán, quien lo rechazó por sugerencia de Mariano Otero. Eduardo Griffon hizo lo propio en 1855. Ambos planes se diseñaron conforme al modelo de Auburn.

En noviembre de 1867, el Congreso determinó los mecanismos para obtener fondos suficientes, dolor de cabeza de las autoridades responsables de la construcción de una penitenciaría en el Distrito Federal, para iniciar los obras de la penitenciaría y dirigió una excitativa a los gobernadores para que informaran sobre la situación de sus estados con relación a este tema. Un año después, a petición de la representación nacional, la Escuela de Bellas Artes presentó su propuesta, en la cual combinaba los métodos de Filadelfia y Auburn. ${ }^{40}$

En 1871, siendo secretario de Gobernación, José María Castillo Velasco envió a la Cámara de Diputa- dos su iniciativa en la que consideraba que la penitenciaría era "la más noble y santa de las aspiraciones de los hombres". Ese mismo año se expidió el Código Penal mexicano, en el que se prescribía un sistema mixto "basado en los resultados poco satisfactorios obtenidos por la aplicación práctica (sic) de los principios constitutivos de Auburn, Filadelfia y Croffton, consistentes en un mismo medio, la comunicación o el aislamiento para la enmienda de toda clase de delincuentes" ${ }^{41}$ El código dispuso la creación de 5 departamentos: educación correccional, corrección penal, arresto, prisión y libertad preparatoria”.

Al mismo tiempo, en el estado de México, el gobernador Mariano Riva Palacio pretendía hacer lo propio en la entidad. Así tras de censurar por enésima ocasión las condiciones deplorables de las cárceles y los reos, lo que

191, p. 16. En consonancia con esas medidas, las autoridades informaron de que una "plaga de mendigos" asolaba el estado. Su "asquerosa presencia e inoportunas demandas" de limosna originaban en la "gente decente" molestia y desesperación. Por tanto era necesario instrumentar una política de control social más enérgica la cual consistía en recoger y enviar a los mendigos a casas de asilo y corrección, en especial a los niños y los jóvenes. Al mismo tiempo, en 1845, el gobernador del Departamento de México Manuel Rincón decretó la formación del Tribunal de Vagos. Véase Padilla Arroyo, Antonio, 1993, pp. 13-14.

40 Macedo, 1902.

41 Medina y Ormaechea, Antonio. México ante los Congresos Internacionales Penitenciarios, México, Secretaría de Fomento, 1892. 
impedía cualquier mejora y enmienda de estos y en cambio perfeccionaban su carrera en el crimen, exhortó a cada distrito a la edificación del sistema penitenciario, el cual debía girar en torno al tratamiento físico y moral de los delincuentes por medio de la observación médica, la instrucción y el aprendizaje de un oficio. Sin embargo, las medidas de control social se seguían aplicando con suma severidad. Así, en octubre de 1850, el congreso estatal expidió la Ley sobre el modo de juzgar y sentenciar a los vagos. En general dicha ley retomaba disposiciones anteriores y añadía otras que afectaban fundamentalmente a los jóvenes. Así, se especificó que los menores de 16 años estaban obligados a aprender un oficio en un taller o una finca de campo, en tanto no existiera penitenciaría. Los mayores de esa edad se destinarían a obrajes, fábricas de hilados y tejidos o haciendas de campo por un mínimo de dos años. En caso de que no fueran recibidos en esos establecimientos se les obligaría a prestar servicios en obras públicas, "dejándose al prudente arbitrio del jurado, imponerles menos tiempo según los casos y las circunstancias". ${ }^{42}$

En el ámbito nacional, el gobierno mexicano mostró interés por instaurar el sistema penitenciario y por conocer otro tipo de experiencias a nivel internacional y envió delegaciones a los distintos congresos internacionales penitenciarios o bien comisionó a personajes prominentes dedicados a promover un sistema carcelario único. Especialmente importante fue la presencia de nuestro país en 1872, año en que se efectuó el primero de ellos en Londres. Nuestro país fue representado por el doctor Enoch C. Wines, director de cárceles de Estados Unidos, teólogo conservador y fundador del "Movimiento Reformador", que se pro- ponía instalar la disciplina fabril en las masas, "flojas y viciosas" de las ciudades industriales de la posguerra civil". Su movimiento tuvo auge entre 1865 y 1900, en coincidencia con el ascenso del porfiriato. ${ }^{43}$ También estuvo presente en reuniones internacionales sobre caridad y filantropía, en las cuales se exponía Con gran optimismo los avances de México en atención social a los pobres. ${ }^{44}$

Por su parte, en el estado de México también se echaron a andar diversas disposiciones que tenían el propósito de regular la vida carcelaria y poner en práctica el régimen penitenciario, en especial la fundación de escuelas en las

42 Riva Palacio, Mariano. Memoria de gobierno presentada a la H. Legislatura del Estado de México, (Toluca, México), Tip. del Instituto Literario, Toluca, 1871. (Anexo Justicia núm 3); Ruelas García, 1991, pp. 17-18; Padilla Arroyo, Antonio, 1993, p. 15.

43 Olmo, Rosa del. América Latina y su criminología, México, Siglo XXI Editores, 1987, pp. 54-81. México estuvo presente en los tres congresos internacionales: en Londres en 1872, en Estocolmo en 1878 y en Roma en 1885.

44 Archivo General de la Nación (AGNM), Fondo Gobernación, Sección 2a, exps. 880, 19, 1 Y 8851, 3; Sección 1 a., 900, 1,2 Y 903 6, 1. 
cárceles. Así, en 1872, el gobernador Alberto García envió al congreso estatal una iniciativa para crear las escuelas primarias en las j prisiones. Después de debates acalorados en la representación popular se aprobó que esta fuera obligatoria para todos los reos. Punto de especial atención en esa iniciativa fue el referente a la calidad moral y la preparación que debían tener los preceptores. Aunque se estipuló que elección se haría conforme a su "notoria moralidad y preparación”, la decisión de su contratación recaería en los jefes políticos de los distritos, por lo que no se garantizaba una selección demasiado rigurosa y de acuerdo con lo estipulado. Precaviéndose contra tales inconvenientes, la legislatura local dispuso que la aprobación final estaría en manos del Ejecutivo. Para alentar la asistencia de los presos a las escuelas, las autoridades prescribieron que el aprovechamiento escolar y la buena conducta serían elementos a considerar para disminuir las penas. No se sabe con exactitud si tales estímulos o la obligatoriedad de asistir a las escuelas fueron resortes para propiciar el interés de los reos por su instrucción, pero dos meses de aprobada la iniciativa, las escuelas rebosaban de alumnos deseosos de adquirir nuevos conocimientos. Para el mes de julio se tenían registrados 1083 alumnos inscritos.

En este sentido, puede afirmarse que se daba un paso más en la integración de la educación en el sistema penitenciario. Años después, las autoridades estatales ordenaron la creación de la Junta Protectora de Cárceles, la cual tenía entre sus propósitos procurar el mejoramiento moral y la rehabilitación de los presos. Por medio del trabajo carcelario y el registro escrupuloso de la conducta de los presos, en especial de su asistencia a las escuelas, dicha junta pretendió aplicar dos premisas fundamentales del sistema penitenciario. En el campo educativo instauró el mecanismo de premios para los alumnos-presos más aventajados y la realización de concursos escolares. Para las autoridades esos mecanismos eran una oportunidad inigualable para exhibir las dotes y los adelantos que habían logrado los reos. El periódico La Ley aseguraba que no había mejor prueba de la rehabilitación de los presos que la educación y los productos del trabajo que exhibían en ocasiones tan solemnes. En efecto, para los responsables del cuidado de los presos no faltaban las muestras del apego que los presos tenían por su preparación. Así, no paso desapercibida la petición de 48 presos de la cárcel del Distrito de Zumpango, quienes solicitaban a la Junta Protectora que se ampliara la esfera de los conocimientos, pues se limitaban al conocimiento de las obligaciones del hombre, el catecismo político constitucional y moral y el ejercicio de la lectura, escritura y aritmética. ${ }^{45}$

En realidad, tales disposiciones iban en el sentido de normar varios aspectos de la realidad carcelaria, lo cual fue un síntoma de un acontecimiento 
fundamental: el predominio que estaba alcanzado la privación de la libertad y con ella el espacio de segregación por excelencia, la cárcel moderna. El significado de tal acontecimiento se enmarcó dentro de procesos socia- les y políticos más generales. La privación de la libertad como la "reina de las penas" explica el esfuerzo de ensayar la idea de la rehabilitación del preso y con ella el lugar de la educación penitenciaria en este proceso de transformación social. La estabilidad y el control social que imponía la élite política permitió poner a prueba la cárcel como el eje de esa metamorfosis. Así, en 1878, el gobernador Juan N. Mirafuentes informó que la seguridad pública era una realidad y no se había quebrantado sensiblemente. Para prueba un botón: la disminución de los delitos. Para el gobernador, tal situación se debía a la difusión de la educación entre las clases pobres y, por añadidura, había logrado moralizarlas, elevarlas al rango de la ciudadanía, convertirlas en amantes de la paz y el trabajo. ${ }^{46}$

En este marco, Mirafuentes informó que 903 reos asistían regularmente a las escuelas de las cárceles de los distritos, siendo las más concurridas las de Cuautitlán y Toluca con 116 respectivamente, entre hombres y mujeres. Para 1886, el número de presos se incrementó a 1321 (1277 hombres y 44 mujeres), aunque las escuelas habían visto disminuir el número de asistentes, 475, con la salvedad de que las autoridades de las cárceles de Chalco, Lerma y Tlalnepantla no habían reportado ninguna información.

Bajo el largo periodo de gobierno de José Vicente Villada, el papel de las escuelas en las cárceles se preciso aún más como parte fundamental del sistema penitenciario. Para Villada, la escuela tenía el objetivo de propiciar en el preso una profunda reflexión acerca de sus delitos y errores y con ello

46 En estos años la pena de privación de la libertad se convirtió en una práctica cada vez más usual. Así, por ejemplo, de un total de 290 reos sentenciados en las jefaturas políticas del estado de México se aplicó dicha pena a 32 individuos, aunque seguía siendo alta la cifra de sentenciados a la pena de muerte, con un total de 34. De éstos 32 fueron indultados y conmutada su pena por la de prisión. Así, en 64 casos se ejecutó la pena de privación de la libertad. No puede dejar de notarse el alto número de de absueltos, 83 , porque fue un reflejo de la dureza de la política de seguridad pública seguida por las autoridades. En este sentido también puede interpretarse el gran número de individuos dedicados al mantenimiento de la seguridad. Los miembros de fuerzas de la Gendarmería, celadores y policía municipal contabilizaban 12651, además de dos escoltas para vigilar los caminos de Toluca a Sultepec y de Toluca al Valle del mismo nombre que ascendían a 2000 integrantes, en un estado que se ufanaba del bajo grado de criminalidad. Memoria presentada a la H. Legislatura del estado de México por el C. Gobernador Constitucional, General Juan N. Mirafuentes, correspondiente al primer año de su administración, Toluca, Imprenta del Instituto Literario, dirigida por Pedro Martínez, 1878, pp. 42-43. 
reintegrarlos al seno de la familia y la sociedad. Consideraba que el trabajo carcelario era el complemento indispensable para la regeneración del preso por lo que ordenó la apertura de los talleres de carpintería, ebanistería, tipografía zapatería y estableció 12 telares para la fabricación de mantas. En cuanto al funcionamiento de las escuelas, en su primera administración informó de la existencia de 9 cárceles en todo el territorio del estado con una asistencia promedio de 355. En ese sentido, fortaleció la práctica de los certámenes escolares para estimular la asistencia de los presos. Apuntó que entre 1890 y 1892 más de $2 / 3$ partes de los alumnos habían aprobado sus exámenes, lo cual era una prueba de que la educación iba supliendo "a la rudez de las inteligencias" ${ }^{37}$

Un paso fundamental en el afianzamiento de la educación penitenciaria fue la erección de la escuela correccional para hombres y mujeres menores de 15 años en 1894. La escuela se dividió en dos departamentos para alojar hombres y mujeres. Parte sustancial de la escuela fue el establecimiento de talleres y la prescripción de ejercicios militares. Los primeros corrigendos fueron en promedio 98, 86 niños y 12 niñas procedentes de los distritos del estado. Bajo la organización militar se organizó el departamento de hombres, el cual contaba con una escuela de instrucción primaria y talleres de sastrería, imprenta, herrería, telares y zapatería, entre otros. El aprendizaje del oficio se determinaba por el director del local, quien tomaba en cuenta la inclinación o las habilidades del menor a fin de asignarle el arte u oficio que debía aprender. En ellas se alojaba a niños y niñas consignados por las autoridades judiciales o administrativas, así como menores enviados por sus padres o tutores fuera por estar imposibilitados para procurarles sustento o por su "mal comportamiento”, quienes debían cubrir una pensión mensual que podría ser cubierto por las autoridades estatales. Según Villada, la mayoría de los corrigendos se encontraban en el primero caso, lo cual explicaba el perfil de los menores: su pobreza y no su falta de moralidad los conducía a permanecer en la escuela correccional. Por otro lado, el número de escuelas en las cárceles ascendió a 15. En ellas recibieron instrucción 2 mil 242, entre las que destacaron las cárceles de Tenancingo, 315, Chalco, 306 y Valle de Bravo $289^{48}$

47 Memoria de la administración pública del estado de México presentada a la XV Legislatura por el Gobernador Constitucional, General José Vicente Villada de 1889 a 1893, Toluca, Imprenta, Litografía y Encuadernación de la escuela de Artes y Oficios, 1893, pp. 200-201

48 Memoria que el C. Gobernador Constitucional del estado de México Gral. José Vicente Villada presenta a la H. Legislatura del mismo, dando cuenta de sus actos administrativos durante el cuatrienio de 1893 a 1897, Toluca, Oficina Tipográfica del Gobierno en la Escuela de Artes y Oficios, 1897, pp. 24, 149 Y 195. 
Finalmente, para la última administración de Villada, la suerte de las cárceles varió ostensiblemente y, por añadidura, la educación penitenciaria sufrió altibajos. En todo caso, la educación se había convertido en un elemento central del sistema penitenciario, aun- que las disposiciones carcelarias en la práctica fueran letra muerta. El aumento de presos con la creación de la Cárcel Central del Estado en 1898 propició el abatimiento de las condiciones de vida de los reos y provocó la caída de la matrícula escolar. De hecho, las cárceles que habían tenido escuelas y que eran parte del motivo de orgullo para las autoridades carcelarias tuvieron que cerrarlas. Tal fue el caso de los distritos de Tenango, Tlalnepantla, Toluca, Temascaltepec, Lerma y Valle de Bravo. En las jurisdicciones que existían la educación se redujo a impartir el primer grado de instrucción primaria, lo cual se justificó con el argumento de que los presos eran analfabetos e indígenas en su mayoría. ${ }^{49}$

El funcionamiento del sistema penitenciario pronto mostró las contradicciones que encerraba. Para finales del porfiriato, las cárceles se parecían más a los cuadros que los primeros gobernantes del estado de México habían denunciado: los presos vivían hacinados y en permanente promiscuidad, no había separación entre los distintos tipos de reos y los vicios se reproducían. En gran medida, tal situación se debió a una mirada distinta sobre la función de la cárcel. Esta tendría como función primordial el castigo y, por ende, atemorizar a los futuros delincuentes, mientras que se fortalecían las instituciones de prevención del crimen mediante el establecimiento de Escuelas de Artes y Oficios, las escuelas nocturnas para adultos, campañas antialcohólicas entre los obreros y obreras, etcétera. El círculo del control social sobre las clases pobres se cerraba.

49 Cfr. Ruelas García, et al, 1991, pp. 32-35; Padilla Arroyo, 1993, pp. 36-48. 